\title{
Endoscopic ultrasound combined with ERCP to treat cystic-duct-remnant stone
}

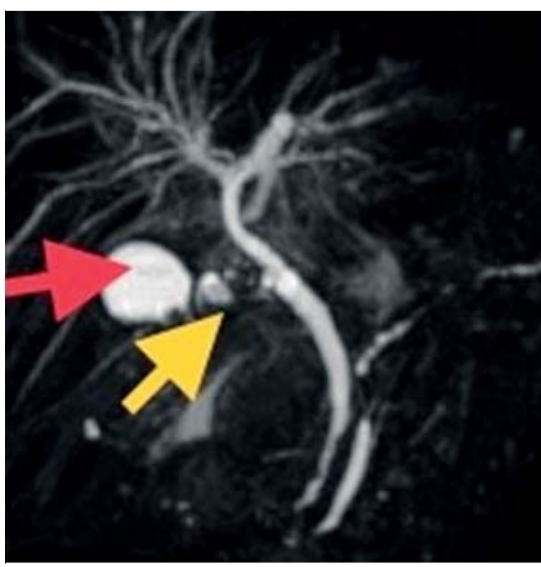

- Fig. 1 Magnetic resonance cholangiopancreatogram revealed multiple stones in the cystic duct remnant (containing part of gallbladder neck and cystic duct; red arrow shows stones in the neck of remnant gallbladder and yellow arrow shows stones in the cystic duct).

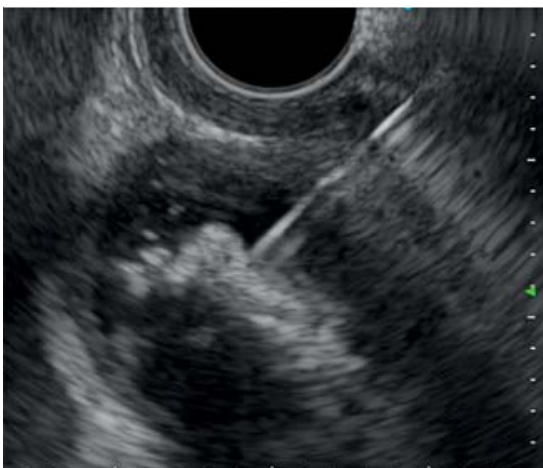

- Fig. 2 Successful endoscopic ultrasound-guided cystic duct remnant puncture accessed from the gastric antrum.

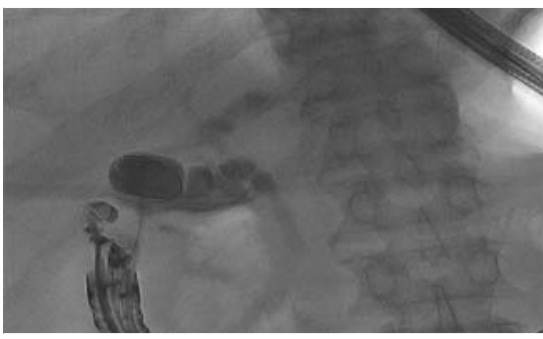

Fig. 3 A guidewire curled inside the cystic duct remnant.

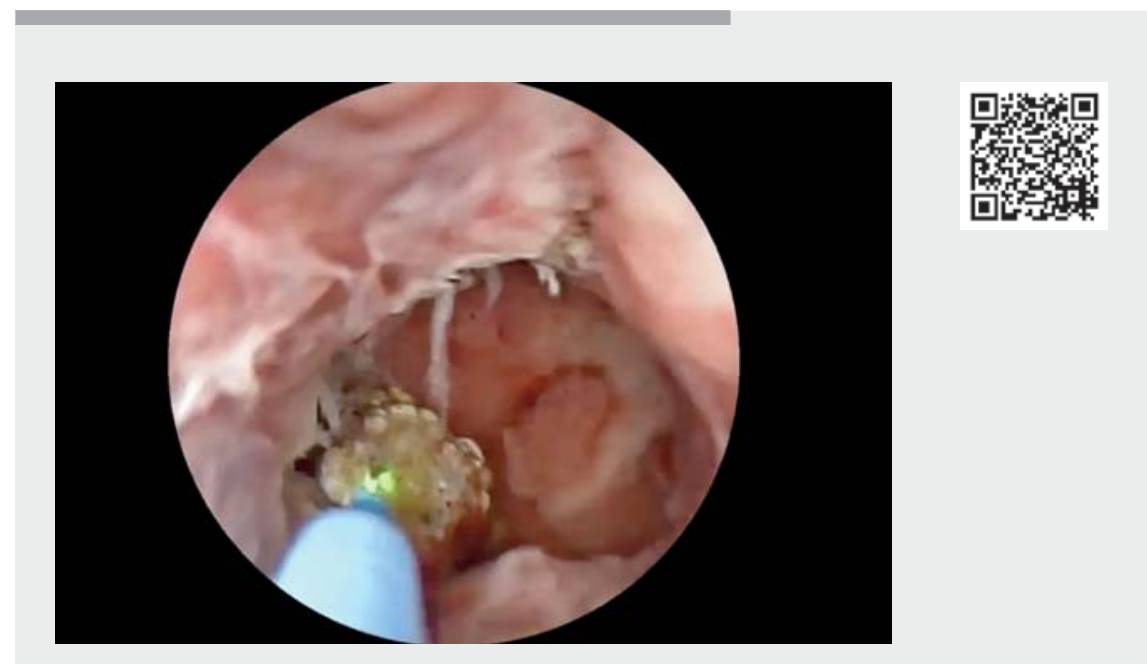

Video 1 Two-session endoscopic treatment starting with endoscopic ultrasoundguided puncture of cystic-duct-remnant and fistula tract creation. The second endoscopic session was to fragment the residual stone and exchange the metallic stent for a transpapillary cystogastric stent.

A 68-year-old man who had undergone complicated cholecystectomy 18 years ago presented with right upper quadrant abdominal pain and a high-grade fever. His complete blood count, liver function tests, and pancreatic enzyme levels were within normal limits. The broad-spectrum antibiotic combination of piperacillin and tazobactam was administered intravenously for 5 days until pain and fever subsided. A magnetic resonance cholangiopancreatogram ( $\triangleright$ Fig. 1 ) revealed a few $1-1.5 \mathrm{~cm}$ gallstones in the cystic duct remnant and none in common bile duct. The patient declined another cholecystectomy and chose an endoscopic treatment.

Endoscopic ultrasound-guided drainage of the cystic duct remnant with tentative stone removal was attempted. An echoendoscope together with a 19G needle was introduced into the closest area between the remnant and upper $\mathrm{Gl}$ tract; in this case, the gastric antrum was chosen ( $\triangleright$ Fig. 2). After confirmation by contrast injection, a guidewire was curled in the remnant ( $\triangleright$ Fig. $\mathbf{3}$ ) and then a 6-Fr cystotome was used to create the tract. A 6-mm dilation balloon was used to expand the tract diameter. Then a $60 \times 10$-mm fully covered self-expandable metallic stent was inserted to maintain the fistula for 2 months ( $>$ Video 1 ). Subsequently, another session of endoscopic treatment was done, the metallic stent was removed, and a naso-gastroscope was inserted into the fistula. A $1.5-\mathrm{cm}$ stone was seen in the cystic duct remnant, and because there was no accessory to pass to the small channel of this scope, laser lithotripsy was performed to fragment the stone ( $\triangleright$ Fig.4). Finally, a 7-Fr $\times 15-\mathrm{cm}$ double pigtail stent was inserted from the ampulla traversing the cystic duct and positioned in the cystic duct remnant ( $>$ Fig.5). A small forceps was used to adjust the other end of the stent to maintain the fistula tract, and this end was left in the stomach. The patient reported no further biliary tract infection during the 2-year follow-up.

Endoscopy_UCTN_Code_TTT_1AS_2AD 


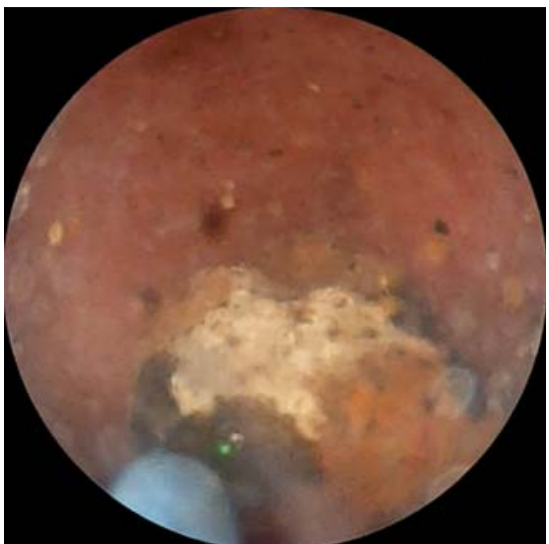

- Fig. 4 Laser lithotripsy of a remnant stone via the accessory channel of a nasogastroscope.

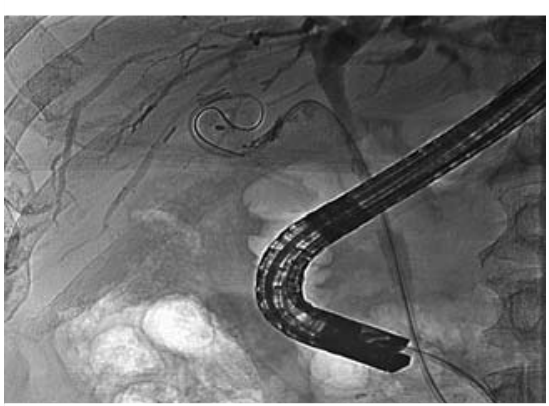

- Fig. 5 A 7- $\mathrm{Fr} \times 15-\mathrm{cm}$ double pigtail plastic stent was inserted from the ampulla traversing the cystic duct with the proximal end placed in the cystic duct remnant (this end was eventually pulled to the antrum to maintain the fistula tract).
The authors declare that they have no conflict of interest.

\section{The authors}

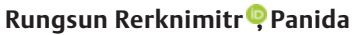

Piyachaturawat, Wiriyaporn Ridtitid,

\section{Natee Faknak}

Division of Gastroenterology, Department of Medicine, Faculty of Medicine, Chulalongkorn University, Bangkok, Thailand

\section{Corresponding author}

\section{Rungsun Rerknimitr, MD}

Division of Gastroenterology, Department of Internal Medicine, Faculty of Medicine, Chulalongkorn University, Bangkok 10310 , Thailand

Fax: +66-2-252-7839

ERCP@live.com

\section{Bibliography}

Endoscopy 2022; 54: E585-E586

DOI 10.1055/a-1704-7697

ISSN 0013-726X

published online 21.12.2021

(c) 2021. Thieme. All rights reserved.

Georg Thieme Verlag KG, Rüdigerstraße 14, 70469 Stuttgart, Germany

\section{ENDOSCOPY E-VIDEOS}

https://eref.thieme.de/e-videos

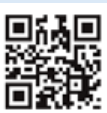

Endoscopy E-Videos is an open access online section, reporting on interesting cases and new techniques in gastroenterological endoscopy. All papers include a high quality video and all contributions are freely accessible online. Processing charges apply (currently EUR 375), discounts and wavers acc. to HINARI are available.

This section has its own submission website at https://mc.manuscriptcentral.com/e-videos 